\title{
Method to adjust Institute of Transportation Engineers vehicle trip-generation estimates in smart-growth areas
}

\author{
Robert J. Schneider ${ }^{\text {a }}$ \\ University of Wisconsin-Milwaukee
}

Susan L. Handy ${ }^{c}$

University of California, Davis

\author{
Kevan Shafizadeh ${ }^{\text {b }}$ \\ California State University, Sacramento
}

\begin{abstract}
This paper describes a practical method of adjusting existing Institute of Transportation Engineers (ITE) estimates to produce more accurate estimates of motor-vehicle trip-generation at developments in smartgrowth areas. Two linear regression equations, one for an A.M. peak-hour adjustment and one for a P.M. peak-hour adjustment, were developed using vehicle trip counts and easily measured site and surrounding area context variables from a sample of 50 smart-growth sites in California. Many of the contextual variables that were associated with lower vehicle trip generation at the smart-growth study sites were correlated. Therefore, variables representing characteristics such as residential population density, employment density, transit service, metered on-street parking, and building setback distance from the sidewalk were combined into a single "smart-growth factor" that was used in the linear regression equations. The A.M. peak-hour and P.M. peak-hour adjustment equations are only appropriate for planning-level analysis at sites in smart-growth areas. In addition, the method is only appropriate for single land uses in several common categories, such as office, mid- to highdensity residential, restaurant, and coffee/donut shop. The method uses data from California, but the methodological approach could provide a framework for adjusting ITE trip-generation estimates in smart-growth areas throughout the United States.
\end{abstract}

\section{$1 \quad$ Introduction}

The California Environmental Quality Act (CEQA) and other state, federal, and local laws require the identification, analysis, and mitigation of transportation-related impacts of proposed land-use projects. The first step in preparing a transportation impact analysis is to estimate the number of trips by motorized vehicles and other modes of travel that may result from a proposed land-use project-a process commonly referred to as "trip generation." Currently, most trip-generation analyses estimate motor-vehicle trips using rates published by the Institute of Transportation Engineers (ITE), a national professional organization.

ITE's trip-generation rates typically relate vehicle trip counts to a measure of building size (e.g., gross square footage, number of units) for a particular land-use classification. Most of the rates are based on vehicle counts obtained at suburban locations that may or may not have transit or bicycle and pedestrian facilities, and ITE guidelines state that these rates should not be used for land-use projects located in urban areas near transit and within easy walking distance of other land uses (ITE 2004). In other words, projects in "smart-growth" areas are not covered by the current industry practice. The absence of

a rjschnei@uwm.edu bshafizadeh@csus.edu cslhandy@ucdavis.edu

Copyright 2015 Robert J. Schneider, Kevan Shafizadeh, and Susan L. Handy

http://dx.doi.org/10.5198/jtlu.2015.416

ISSN: 1938-7849 | Licensed under the Creative Commons Attribution - NonCommercial License 3.0.

The Journal of Transport and Land Use is the official journal of the World Society for Transport and Land Use (WSTLUR) and is published and sponsored by the University of Minnesota Center for Transportation Studies. 
an accepted trip-generation method is a problem for communities that need to assess the transportation impacts of smart-growth land-use projects.

One approach that has been used to address this problem is to apply the available, suburban-based ITE rates to smart-growth developments. This approach ignores ITE guidance, but it is the only option known to many communities. Not surprisingly, many recent studies of urban infill, mixed-use, transitoriented, and other smart-growth developments indicate that this approach overestimates the number of vehicle trips generated by more than 25 percent (Tindale Oliver and Associates 1993; Steiner 1998; Muldoon and Bloomberg 2008; Arrington and Cervero 2008; Kimley Horn Associates 2009; Bochner et al. 2011; Schneider et al. 2013a). This current practice leads communities to overprescribe motor vehicle infrastructure in smart-growth areas, resulting in wider roadways, more turning lanes, more parking spaces, and larger parking lots than necessary. This motor vehicle infrastructure may also impose higher costs on developers than would be assessed to provide a balanced set of automobile, pedestrian, public transit, and bicycle accommodations, creating a disincentive for smart-growth land-use projects.

A second approach to overcome the lack of an accepted trip-generation method for smart-growth areas is to make adjustments to the existing ITE rates or develop a completely different trip-generation technique. This paper describes the development of a new, practical method to adjust existing ITE rates and estimate motor-vehicle trip generation for smart-growth land-use development projects. While the method is based on a relatively small sample of data collected in California, the methodological approach may provide a framework for adjusting ITE vehicle trip-generation estimates in smart-growth areas throughout the United States.

\section{$2 \quad$ Literature review}

Several trip-generation methods have been developed as alternatives to the standard ITE approach. These methods include:

- ITE Multi-Use Method (ITE 2004). This method is based on vehicle trip data collected at three multi-use sites in Florida during the 1990s and is presented in Chapter 7 of the ITE Trip Generation Handbook.

- NCHRP 8-51 Method (Bochner et al. 2011). This method is an enhancement of the current ITE handbook Multi-Use Method based on data collected at six sites and tested at three different sites.

- United States Environmental Protection Agency (EPA)/San Diego Association of Governments (SANDAG) Method (SANDAG 2010). This method was originally developed by the EPA using household travel survey data from large multi-use sites in six metropolitan areas in the United States. SANDAG adopted this method.

- URBEMIS ("Urban Emissions") Method (Jones and Stokes Associates 2007). This method, developed by the California Air Quality Management Districts and California Department of Transportation, makes adjustments to ITE trip-generation estimates based on variables such as density, mixed-use, transit, street connectivity, bicycle and pedestrian facilities, and transportation demand.

- Metropolitan Transportation Commission (MTC) Survey Method (MTC 2006). This method is based on the MTC 2000 Travel Survey and makes adjustments to ITE rates using variables such as density and proximity to rail or ferry transit.

- San Francisco Method (City and County of San Francisco 2002). This method estimates person-trips by mode (e.g., auto, transit, walk, other). Persontrip mode shares are based on data from the San Francisco Citywide Travel Behavior Survey and traffic analyses from various environmental impact reports. 
- New York City (Rizavi and Yeung 2010). New York's City Environmental Quality Review method recommends that transportation impact assessments be based on original pedestrian, bicycle, transit, and automobile person-trip data collected at a nearby site or a study already conducted at a similar New York City land use with comparable travel characteristics before considering the ITE Trip Generation method.

All of these tools have the potential to perform better than the suburban-based ITE Trip Generation method for predicting vehicle trip generation in smart-growth areas. Shafizadeh, et al. (2012) evaluated the operational characteristics and accuracy of the first five methods listed above (the San Francisco and New York methods were not considered to have broad applicability outside of these cities). Operational characteristics were evaluated by a panel of experts, according to criteria in the following categories: 1) ease of use, 2) sensitivity to key smart-growth elements, 3) input requirements, 4) output features, and 5) usability of the approach in helping to define smart-growth projects based on their performance. While each of the methods has advanced the state-of-the-practice, this evaluation identified practical limitations to using each of the methods. Shafizadeh et al. (2012) also used motor vehicle count and intercept survey data from 22 California sites to evaluate the predictive accuracy of each of these alternative approaches. None of the alternative methods provided results that were consistently more accurate than any of the other test methods, but all of these methods still performed better than the existing ITE method.

Other promising methods of adjusting ITE motor vehicle trip-generation estimates are being developed. For example, Clifton et al. (2012a) identified eight regional built-environment categories in the Seattle region and used a binary logit model to estimate the probability of choosing a personal vehicle versus using another mode for trips in each built-environment category. In general, built-environment categories with higher density and more mixed land uses had greater vehicle trip reductions than suburban and exurban categories. In addition, Clifton et al. (2012b) combined trip-generation data from establishment surveys in the Portland, Ore., region with land-use classification and community context variables to develop models to adjust ITE P.M. peak-hour vehicle-trip rates at "high-turnover (sit-down) restaurants," "24-hour convenience markets," and "drinking establishments"—as defined by the existing ITE approach.

The United Kingdom and New Zealand have also developed multimodal trip generation methods based on large databases for urban areas and provide actual trip rates rather than adjustments to ITE rates (Trip Rate Information Computer System 2013; New Zealand Trips and Parking Database Bureau 2013). However, since the trip-generation contexts are different in these countries (e.g., different transportation facility design guidelines, transportation costs, and cultures), they are not likely to be applicable in the United States. Additional details about alternative trip-generation methods are summarized by Shafizadeh et al. (2012) and Clifton et al. (2012a).

\section{$3 \quad$ Method development}

Our method to adjust ITE vehicle trip-generation estimates is based on data from more than 50 smartgrowth study sites in California. It consists of two separate regression models, one that produces a morning (A.M.) peak-hour adjustment and one that produces an afternoon (P.M.) peak-hour adjustment. The sections below provide an overview of the study sites, smart-growth context variables, and modeling approach. Additional details about the specific locations of study sites, site development intensity (e.g., residential dwelling units, commercial gross square feet), differences between actual and ITE-estimated trips, individual explanatory variables, statistical modeling considerations, validation, and other aspects of method development are available in the project report (Schneider et al. 2013b). Note that the term "trips," used in this study to represent the total number of inbound plus outbound trips generated by each 
study site, is functionally equivalent to the term "trip-ends," which is used by ITE (ITE 2004). In addition, the term "study site" refers to all 65 locations where data were collected for the study. Most of these data were from individual land uses. Some of these individual land uses were the only use on a property; others were part of a multi-use development but were isolated for data collection. Some data were also collected on the boundary of properties with more than one land use (i.e., multi-use developments).

\subsection{Study sites}

Trip-generation data were gathered from sites in the Los Angeles, San Diego, San Francisco, Oakland, and Sacramento regions that met specific smart-growth criteria. These study regions ranged in size from fewer than 2.2 million people at an average density of fewer than 200 people per square $\mathrm{km}$ (Sacramento Metropolitan Statistical Area) to more than 12 million people at an average density of more than 1000 people per square km (Los Angeles Metropolitan Statistical Area). Study sites in the less-populated regions tended to be concentrated closer to the central business district than study sites in the morepopulated regions because only the cores of less-populated regions met the minimum criteria to be classified as smart growth.

Table 1: Sources of trip generation data at study location.

\begin{tabular}{|c|c|c|c|c|}
\hline Source & \#of Study Sites & $\begin{array}{c}\text { Data Collection } \\
\text { Timeframe }\end{array}$ & $\begin{array}{c}\text { Data Collection } \\
\text { Approach }\end{array}$ & $\begin{array}{c}\text { Source for } \\
\text { More Detailed } \\
\text { Information }\end{array}$ \\
\hline EPA MXD Study & 3 & Fall 2007 & $\begin{array}{l}\text { Pneumatic tube } \\
\text { counts }\end{array}$ & US EPA (2013) \\
\hline TCRP Report 128 & 5 & Spring 2007 & $\begin{array}{l}\text { Pneumatic tube } \\
\text { counts }\end{array}$ & $\begin{array}{l}\text { Arrington and } \\
\text { Cervero (2008) }\end{array}$ \\
\hline Caltrans Infill Study & 22 & $\begin{array}{c}\text { Spring } 2006 \\
\text { Spring } 2007 \\
\text { Fall } 2007 \\
\text { Spring } 2008 \\
\text { Fall } 2008\end{array}$ & $\begin{array}{l}\text { Door counts and } \\
\text { intercept surveys }\end{array}$ & $\begin{array}{l}\text { Kimley Horn and } \\
\text { Associates (2009) }\end{array}$ \\
\hline $\begin{array}{l}\text { San Diego Association of Governments } \\
\text { (SANDAG) MXD Study }\end{array}$ & 6 & $\begin{array}{c}\text { Fall } 2008 \\
\text { Spring } 2009\end{array}$ & $\begin{array}{l}\text { Pneumatic tube } \\
\text { counts }\end{array}$ & SANDAG (2010) \\
\hline $\begin{array}{l}\text { Fehr and Peers data collection at multi- } \\
\text { or mixed-use sites }\end{array}$ & 2 & Fall 2010 & $\begin{array}{l}\text { Pneumatic tube } \\
\text { counts }\end{array}$ & $\begin{array}{c}\text { Data were } \\
\text { provided } \\
\text { directly from } \\
\text { Fehr and Peers } \\
\text { Transportation } \\
\text { Consultants } \\
(2010)\end{array}$ \\
\hline Research team field data collection & 30 & Spring 2012 & $\begin{array}{l}\text { Door counts and } \\
\text { intercept surveys }\end{array}$ & $\begin{array}{l}\text { Schneider et al. } \\
\qquad(2013 b)\end{array}$ \\
\hline
\end{tabular}

Since trip-generation data are relatively rare in smart-growth areas, the research team, with assistance from a panel of practitioners, compiled recent data (2006 or later) from as many sites as possible. Site trip-generation counts came from several different sources, including field data collection by the research team in Spring 2012. The sources and data collection approaches used at these sites are summarized in Table 1. 


\section{Sites used for model development}

Overall, 46 of the study sites were used for A.M. model development, and 50 of the sites were used for P.M. model development. These sites represented common land-use categories, including mid- to highdensity residential, office, coffee/donut shop, and general retail, as defined by ITE (Table 2).

\section{Sites used for model validation}

Some of the study sites were located close to another study site, and a few of the individual land uses where data were collected were actually part of the same development. The land uses that were a part of the same development shared nearly all of the same site and surrounding area characteristics, and including them together in the model would violate the statistical modeling assumption that each data record

Table 2: Land-use categories for study sites.

\begin{tabular}{|l|c|c|}
\hline General Land-Use Category & A.M. Model & P.M. Model \\
\hline Mid-to High-Density Residential & 20 & 20 \\
\hline Office & 11 & 12 \\
\hline Coffee/Donut & 3 & 3 \\
\hline Multi-Use Development & 11 & 11 \\
\hline Retail & 0 & 3 \\
\hline Other (Restaurant) & 1 & 1 \\
\hline Total Sites & $\mathbf{4 6}$ & $\mathbf{5 0}$ \\
\hline
\end{tabular}

was independent. To avoid this problem, sites within one-quarter mile of other sites and the second or third targeted land use within the same development were set aside for validation. For study sites in close proximity to each other, a random process was used to choose which site was included in the analysis versus the validation dataset. This process produced 11 sites for A.M. model validation and 13 sites for P.M. model validation.

\subsection{Modeling approach}

The adjustment models were designed to be easy to understand and apply. Therefore, they used variables that are commonly available or could be measured easily with tools available to most practitioners.

\section{Dependent Variable}

The dependent variable in both the A.M. and P.M. peak-hour adjustment models was based on the ratio of the actual number of vehicle trips observed at each study site to the number of vehicle trips estimated from standard ITE rates. A natural log transformation was applied to this ratio to create the dependent variable: $\ln$ (actual vehicle trips/ITE-estimated vehicle trips).

This variable is easy to interpret. Smart-growth sites that have fewer vehicle trips (i.e., a greater difference between actual and ITE-estimated trips) have a smaller ratio of actual to ITE-estimated trips. The difference between actual and ITE-estimated trips could have been used as the dependent variable, but the ratio was selected because it controls for the size of sample sites (i.e., large sites tend to have large differences in the number of trips). The natural-log transformation was applied to the ratio to improve model fit. Descriptive statistics for the dependent variables used in the A.M. and P.M. models are shown in Table 3.

On average, the ratio of actual vehicle trips to ITE-estimated trips was 0.65 for the 46 sites studied during the A.M. peak hour (i.e., the ITE method estimated 1.5 times too many automobile trips) and was 0.58 for the 50 sites studied during the P.M. peak hour (i.e., the ITE method estimated 1.7 times 
Table 3: Dependent variable descriptive statistics.

\begin{tabular}{|l|r|r|r|r|r|}
\hline Variable & \multicolumn{1}{|c|}{ N } & \multicolumn{1}{c|}{ Minimum } & Maximum & \multicolumn{1}{c|}{ Mean } & Std. Dev. \\
\hline Actual A.M. vehicle trips/ITE-estimated A.M. vehicle trips & 46 & 0.112 & 3.289 & 0.650 & 0.513 \\
\hline $\ln$ (actual A.M. vehicle trips/ITE-estimated A.M. vehicle trips) & 46 & -2.187 & 1.190 & -0.648 & 0.664 \\
\hline Actual P.M. vehicle trips/ITE-estimated P.M. vehicle trips & 50 & 0.090 & 2.215 & 0.583 & 0.356 \\
\hline $\ln$ (actual P.M. vehicle trips/ITE-estimated P.M. vehicle trips) & 50 & -2.413 & 0.795 & -0.705 & 0.603 \\
\hline
\end{tabular}

too many automobile trips). If the ITE method overestimated vehicle trip generation by 1.5 or 1.7 times at all smart-growth sites, it would be simple to apply an adjustment factor (just divide by 1.5 or 1.7) to obtain the correct vehicle trip estimate. Yet, the discrepancy between ITE estimates and actual vehicle trips depended on the land use at the study site (Schneider et al. 2013a). It was also possible that the discrepancy depended on other site and surrounding built-environment variables. Therefore, to adjust ITE estimates correctly, the smart-growth adjustment models needed to consider a variety of influences on travel behavior.

\section{Explanatory Variables}

While the literature has identified many variables that link the surrounding context to travel behavior (Handy et al. 2008; Levinson and Krizek 2008; Rodríguez et al. 2008; Ewing and Cervero 2010; Clifton et al. 2012b), only a subset of these variables are practical for trip-generation applications. The modeling process focused on variables that are readily available or relatively easy to measure. Several categories of contextual variables were hypothesized to be associated with the ratio of actual to ITEestimated vehicle trips, including:

- Land-use classification (e.g., office, coffee/donut shop).

- Site characteristics (e.g., off-street surface parking, building setback distance).

- Adjacent street characteristics (e.g., number of lanes, pedestrian and bicycle facilities).

- Surrounding area characteristics (e.g., population and employment density, neighborhood socioeconomic characteristics).

- Proximity characteristics (e.g., distance to transit and other activity locations such as restaurants, retail, and university campuses).

Descriptive statistics for these explanatory variables are provided in the project report (Schneider et al. 2013c).

After the database of potential explanatory variables was assembled, the research team examined correlations between the explanatory variables and the ratio of actual to ITE-estimated trips, as well as correlations among the explanatory variables. This process helped to identify which explanatory variables were the most promising to include in models (i.e., those with relatively high correlations with the dependent variable) and helped to identify related sets of explanatory variables.

\section{Modeling Process}

Initially, the research team developed several ordinary least squares models to identify statistical associations between the most promising individual explanatory variables and the dependent variable for the A.M. peak hour and the P.M. peak hour. However, this approach pitted many correlated smart-growth explanatory variables against one another (e.g., if one smart-growth characteristic is present, such as high employment density, others are also likely to be present, such as frequent transit service and metered onstreet parking). The research team used a two-step method to address this problem.

First, factor analysis was applied to data from the 50 P.M. study sites to create a formula for a 
"smart-growth factor" (SGF). Factor analysis is a common technique used in the travel behavior literature to address the challenge of correlated contextual variables (Cervero and Kockelman 1997). The factor analysis extraction was done using principal axis factoring, since this method accommodates variables that are not normally distributed (Costello and Osborne 2005). A single factor explained 49.5 percent of the variation in the data, while the second factor only explained 17.3 percent of the variation, so the single factor was selected as the SGF. All of the factor loadings were substantial (six of the eight variables had factor loadings with absolute values greater than 0.6 , and the lowest absolute value of a factor loading was 0.47 ).

The SGF is a linear combination of eight variables, each standardized to a mean of zero and standard deviation of one and weighted according to its contribution to explaining the variation among the 50 P.M. study sites (Table 4). Variables included in the SGF represent distinguishing characteristics of smart-growth developments. Positive coefficients indicate that increasing the value of the variable produces a higher SGF value, which indicates that the site is more representative of smart-growth; negative coefficients indicate that increasing the value of the variable produces a lower SGF value, which indicates that the site is less representative of smart-growth. Several other variables were also considered as potential components of the SGF (e.g., number of four-way intersections near the site; number of lanes on roadways bounding the site; percentage of households with no vehicles within the census tract at the site). However, after testing alternatives, the eight-variable SGF had the greatest statistical association

Table 4: Smart-growth factor.

\begin{tabular}{|c|c|}
\hline Variable & Coefficient $^{1}$ \\
\hline Residential population within an $804-\mathrm{m}\left(0.5\right.$-mile) straight-line radius $(000 \mathrm{~s})^{2}$ & 0.099 \\
\hline Jobs within an $804-\mathrm{m}\left(0.5\right.$-mile) straight-line radius $(000 \mathrm{~s})^{3}$ & 0.324 \\
\hline Straight-line distance to center of central business district (CBD) (miles) ${ }^{4}$ & -0.138 \\
\hline Average building setback distance from sidewalk (feet $)^{5}$ & -0.167 \\
\hline Metered on-street parking within a $161-\mathrm{m}(0.1$-mile $)$ straight-line radius $(1=y e s, 0=\text { no })^{6}$ & 0.184 \\
\hline Individual P.M. peak-hour bus line stops passing within a $402-\mathrm{m}\left(0.25\right.$-mile) straight-line radius ${ }^{7}$ & 0.227 \\
\hline Individual P.M. peak-hour train line stops passing within a $804-\mathrm{m}\left(0.5\right.$-mile) straight-line radius ${ }^{8}$ & 0.053 \\
\hline Proportion of site area covered by surface parking lots $(0.00 \text { to } 1.00)^{9}$ & -0.080 \\
\hline
\end{tabular}

Notes:

${ }^{1}$ This coefficient is applied to the standardized version of the variable. The value is standardized to a mean of zero and standard deviation of one based on the mean and standard deviation of variable values from the 50 P.M. analysis sites.

${ }^{2}$ The 804-m (0.5-mile) straight-line radius is measured from the center of the site. This measure was calculated in GIS for model development using US Census block group data (2010), but it is also possible to estimate the population within 804-m (0.5-miles) from online sources.

${ }^{3}$ The 804-m (0.5-mile) straight-line radius is measured from the center of the site. This measure was calculated in GIS for model development using US Census block group data (2010), but it is also possible to estimate the employment within 804-m (0.5-miles) from online sources.

${ }^{4}$ Straight-line distance from center of study site to center of the regional central business district (CBD) (in miles; 1 mile $=1.61 \mathrm{~km}$ ).

${ }^{5}$ Average building setback is the average straight-line distance to the sidewalk from all major building entrances (in feet; 1 foot $=0.305 \mathrm{~m}$ ). Major entrances include the main pedestrian entrance and automobile garage entrances.

${ }^{6}$ Metered parking only includes metered on-street parking. Metered off-street surface lots or parking structures are not included. The 161-m (0.1-mile) straight-line radius is measured from the center of the site.

${ }^{7}$ Number of individual bus stop locations on all bus lines that pass within any part of a 402-m (0.25-mile) radius around the study site during a typical weekday P.M. peak hour.

${ }^{8}$ Number of individual train stop locations on all train lines that pass within any part of a 804-m (0.5-mile) radius around the study site during a typical weekday P.M. peak hour.

${ }^{9}$ Proportion of site surface area covered by surface parking lots does not include surface area covered by parking structures. Therefore, sites that only have parking garages should be given a value of 0.00 . 
with the dependent variable, so it was used in the final models.

Means and standard deviations of each SGF component variable were calculated for the 50 P.M. study sites (Table 5). These values are necessary to calculate standardized versions of the variable for estimating and applying the models. For example, if the residential population within $804 \mathrm{~m}$ (0.5 miles) of a site is 15,000 , the value of 15 (in thousands) is standardized using the mean (9.718) and standard deviation (6.811) of this variable (from Table 5). The standardized value is $(15-9.718) / 6.811=0.776$. Then, the contribution of residential population to the overall SGF is the SGF coefficient (from Table 4) multiplied by the standardized value of this variable, or $0.099^{*} 0.776=0.0768$. The final SGF for a site is the sum of the coefficient multiplied by the standardized value for all eight variables.

Second, the site SGF was considered as a potential explanatory variable in a series of ordinary least squares regression models. Other potential explanatory variables represented the land-use classification of the site, proximity to a major university campus, and socioeconomic characteristics of surrounding neighborhood residents. To determine the best possible models, the research team searched for an optimal balance between the overall explanatory power of each model, the statistical significance of the coefficients for individual variables, and the theoretical importance of the variables as predictors of travel behavior

Table 5: Smart-growth factor variable descriptive statistics based on 50 P.M. peak hour study sites.

\begin{tabular}{|l|r|r|r|r|r|}
\hline Variable & $\mathbf{N}$ & Minimum & Maximum & Mean & Std. Dev. \\
\hline $\begin{array}{l}\text { Residential population within an 804-m (0.5-mile) } \\
\text { straight-line radius (000s) }\end{array}$ & 50 & 0.787 & 42.109 & 9.718 & 6.811 \\
\hline Jobs within an 804-m (0.5-mile) straight-line radius (000s) & 50 & 0.487 & 136.400 & 24.351 & 29.899 \\
\hline $\begin{array}{l}\text { Straight-line distance to center of central business district } \\
\text { (CBD) (in miles; 1 mile = 1.61 km) }\end{array}$ & 50 & 0.029 & 40.100 & 7.746 & 9.489 \\
\hline $\begin{array}{l}\text { Average building setback distance from sidewalk (in feet; 1 } \\
\text { foot = 0.305 m) }\end{array}$ & 50 & 0.000 & 524.000 & 76.020 & 115.644 \\
\hline $\begin{array}{l}\text { Metered on-street parking within a 161-m (0.1-mile) } \\
\text { straight-line radius (1=yes, 0=no) }\end{array}$ & 50 & 0.000 & 1.000 & 0.620 & 0.490 \\
\hline $\begin{array}{l}\text { Individual P.M. peak-hour bus line stops passing within a } \\
\text { 402-m (0.25-mile) straight-line radius }\end{array}$ & 50 & 0.000 & 255.000 & 43.420 & 50.836 \\
\hline $\begin{array}{l}\text { Individual P.M. peak-hour train line stops passing within a } \\
\text { 804-m (0.5-mile) straight-line radius }\end{array}$ & 50 & 0.000 & 59.000 & 6.820 & 12.141 \\
\hline $\begin{array}{l}\text { Proportion of site area covered by surface parking lots (0.00 } \\
\text { to 1.00) }\end{array}$ & 50 & 0.000 & 0.500 & 0.063 & 0.124 \\
\hline
\end{tabular}

The final A.M. and P.M. peak-hour models are shown in Table 6. Both models include the SGF and indicator variables for whether or not the study site is an office land use, is a coffee/donut shop land use, is a multi-use development, or is located within one mile of a major university campus.

\section{Modeling Considerations}

The overall fit for each model was in the range of other multivariate models relating travel behavior to the built environment (the adjusted $\mathrm{R}^{2}$-value was 0.294 for the A.M. model and 0.290 for the P.M. model). These adjusted $\mathrm{R}^{2}$-values are lower than many $\mathrm{R}^{2}$-values in the ITE Trip Generation Manual (2012). However, the Trip Generation Manual models express relationships between the number of trips and the size of projects, which, of course, are closely related. In contrast, the models presented here 
Table 6: Final A.M. peak-hour and P.M. peak-hour models.

\begin{tabular}{|c|c|c|c|c|c|c|}
\hline \multicolumn{7}{|l|}{$\begin{array}{l}\text { Dependent Variable = Natural Logarithn } \\
\text { Vehicle Trips }\end{array}$} \\
\hline \multirow[b]{2}{*}{ Model Variables } & \multicolumn{3}{|c|}{ A.M. Model } & \multicolumn{3}{|c|}{ P.M. Model } \\
\hline & Coefficient & t-statistic & p-value & Coefficient & t-statistic & p-value \\
\hline Smart-Growth Factor (SGF) & -0.096 & -0.857 & 0.397 & -0.155 & -1.491 & 0.143 \\
\hline Office land use $(1=$ yes, $0=$ no $)$ & -0.728 & -3.182 & 0.003 & -0.529 & -2.558 & 0.014 \\
\hline Coffee shop land use $(1=$ yes, $0=$ no $)$ & -0.617 & -1.677 & 0.101 & -0.744 & -2.339 & 0.024 \\
\hline Multi-use development $(1=$ yes, $0=$ no $)$ & -0.364 & -1.561 & 0.127 & -0.079 & -0.381 & 0.705 \\
\hline Within 1 mile of university $(1=$ yes, $0=$ no $)$ & -1.002 & -2.285 & 0.028 & -0.311 & -1.099 & 0.278 \\
\hline Constant & -0.304 & -2.460 & 0.018 & -0.491 & -4.469 & 0.000 \\
\hline \multicolumn{7}{|l|}{ Overall Model } \\
\hline Sample Size $(\mathrm{N})$ & \multicolumn{3}{|c|}{46} & \multicolumn{3}{|c|}{50} \\
\hline Adjusted $\mathrm{R}^{2}$-Value & \multicolumn{3}{|c|}{0.294} & \multicolumn{3}{|c|}{0.290} \\
\hline F-Value (Test value) & \multicolumn{3}{|c|}{$4.74(\mathrm{p}=0.002)$} & \multicolumn{3}{|c|}{$4.99(\mathrm{p}=0.001)$} \\
\hline
\end{tabular}

predict an adjustment to trip rates that is independent of size. In other words, the new models account for variation above and beyond the basic effect of size on numbers of trips. In addition, the models in the Trip Generation Manual are based on a more homogeneous sample of sites (isolated, single-use, suburban developments) than the sites used in this study. Therefore, it is not appropriate to make a direct comparison between $\mathrm{R}^{2}$-values in the Trip Generation Manual and the adjusted $\mathrm{R}^{2}$-values for these models.

Small sample sizes presented a challenge for modeling. In particular, some variable parameter estimates were insignificant (e.g., the SGF parameter in the A.M. model had a t-statistic of 0.857; the multi-use development indicator variable parameter in the P.M. model had a t-statistic of -0.381). These insignificant parameters were retained in the model for symmetry between the A.M. and P.M. versions and to ensure the sensitivity of the model to these variables. The ordinary least squares approach was used for simplicity and because it is consistent with the current approach by ITE. Because the primary purpose of the models is to identify an adjustment factor that can be applied to the ITE-estimated vehicle trips, they are useful for practical application despite the small sample size on which they are based. Future efforts to add more study sites to the modeling dataset are likely to improve the accuracy of individual parameter estimates.

The modeling dataset included 11 multi-use development sites. Multi-use developments, by definition, are a combination of several individual land uses. The character of trips generated by multi-use developments may be different than trips generated by the other sites (which were each distinct land uses), so these 11 sites were not ideal candidates for the dataset, but they helped increase the sample size for modeling purposes. The multi-use development indicator variable was included in the models to control for the possible unique influence of these sites (even though it had low statistical significance in the P.M. model). While this variable is important to include in the model to provide unbiased parameter estimates, it should not be used when applying the models to estimate vehicle trip-generation numbers (i.e., the value of this variable is always set to zero when the models are applied). The models are only for single-use sites or single land uses that are part of multi-use sites; the multi-use method described in the ITE Trip Generation Handbook should be used for multi-use sites.

Finally, the overall economic activity levels at each smart-growth study site could have been somewhat different than the activity levels present at the sites in the ITE Trip Generation Manual (2012). Economically robust sites could have higher trip generation and economically depressed sites could have 
lower trip generation than the average trip-generation level assumed by ITE for each land-use classification. It was not possible to control for these possible variations in the modeling process.

\subsection{Model validation}

The models predict the ratio of actual to ITE-estimated vehicle trips at smart-growth sites. For the 46 A.M. study sites, the average model-predicted value was 0.56 (i.e., the ITE method estimated 1.8 times too many vehicle trips), and for the 50 P.M. study sites, the average model-predicted value was 0.52 (i.e., the ITE method estimated 1.9 times too many vehicle trips).

Eleven sites with A.M. peak-hour trip-generation data and 13 sites with P.M. peak-hour trip-generation data were reserved for model validation. The validation sites covered the same general land-use categories as the model development sites, except they did not include any multi-use sites (since the method is not intended for multi-use sites). Validation was done by comparing the model-predicted values with observed values at the validation sites (Figure 1 for A.M. and Figure 2 for P.M.). This comparison showed that the models predicted the smart-growth adjustment fairly well at some validation sites but not at other sites: The model-predicted value was within 50 percent of the observed value at seven of the 11 A.M. sites and seven of 13 P.M. sites. In general, the models tended to overestimate at the validation sites (i.e., sites had fewer vehicle trips than the model predicted; most data points in Figure 1 and Figure 2 are below the diagonal line indicating model-predicted values equal to observed values). Thus, the models tended to produce more conservative adjustments to ITE-estimated vehicle trips than could potentially be justified based on observed data.

\section{Application}

The method was designed to be applied in practice. A user-friendly spreadsheet was created that includes internal formulas with the model equations, making it easy for practitioners to enter input variable values and derive estimated vehicle trips.

Because the models are based on study sites in smart-growth areas, they should be applied only to sites in smart-growth locations. Therefore, the criteria listed in Table 7 have been established to identify sites where it is appropriate to use the models. These criteria are generally more stringent (i.e., more representative of smart-growth) than the minimum values of the variables from sites used for model development. This conservative approach helps to ensure that the locations where the models are applied truly represent smart-growth. Additional details about specific criteria are available in the project report (Schneider et al. 2013c).

\section{$5 \quad$ Future research}

There is currently no commonly accepted methodology in the United States for estimating vehicle tripgeneration rates associated with smart-growth projects. This lack of a commonly accepted methodology makes it very difficult for practitioners to accurately estimate the traffic impacts of such projects or to identify and recommend appropriate or adequate transportation "mitigations," including pedestrian, bicycle, and transit facilities. The models presented in this paper were based on the best trip-generation data available from smart-growth sites in California, which are still relatively limited, so they represent an important step forward that can be followed by future research to improve model accuracy and broaden model applicability. Therefore, it is important to test the models in other urban regions. This will show whether or not the model results are consistent for sites in regions with different spatial structure, density, economic, or climate characteristics than the regions used in this study. Future research could also 
Table 7: Criteria for model application.

\begin{tabular}{|c|c|}
\hline Category & Criteria for Model Application \\
\hline Land-Use Classification & $\begin{array}{l}\text { - Models are recommended for the following ITE Land-Use Codes }{ }^{1} \text { : } \\
\text { o Mid- to high-density residential }(220,222,223,230,232) \\
\text { o Office (710) } \\
\text { o Restaurant }(931,939) \\
{ }^{\circ} \text { Coffee/donut shop (936) } \\
\text { o P.M. model may be appropriate for the following ITE Land-Use } \\
\text { Codes': } \\
\text { o Retail (820, 867, 880) } \\
\text { o Models are not appropriate for special attractor land uses (e.g., stadi- } \\
\text { ums, military bases, commercial airports, major tourist attractions) } \\
\text { within a 402-m (0.25-mile) straight-line radius of the center of the site } \\
\end{array}$ \\
\hline Smart-Growth Development Characteristics & $\begin{array}{l}\text { - Models are recommended only for sites that meet all three of the follow- } \\
\text { ing criteria: } \\
\text { o The area within an } 804-\mathrm{m}(0.5 \text {-mile) straight-line radius of the site is } \\
\text { mostly ( }>80 \%) \text { developed (rural land and open space are "undevel- } \\
\text { oped") } \\
\text { o There is a mix of land uses within a } 402-\mathrm{m}(0.25 \text {-mile) radius of the } \\
\text { site (i.e., there are at least two different major land-use categories, such } \\
\text { as residential, office, retail, industrial, etc.) } \\
\text { o J }>4,000 \text { and } \mathrm{R}>(6,900-0.1 \mathrm{~J}) \text {, where } \mathrm{J} \text { is the number of jobs within an } \\
804-\mathrm{m}(0.5-\mathrm{mile}) \text { radius of the site and } \mathrm{R} \text { is the number of residents } \\
\text { within an } 804-\mathrm{m}(0.5 \text {-mile) radius of the site }\end{array}$ \\
\hline Smart-Growth Transportation Characteristics & $\begin{array}{l}\text { - Models are recommended only for sites that meet the following smart- } \\
\text { growth transit service criterion: } \\
\text { o During a typical weekday P.M. peak hour, there is transit service with } \\
\text { at least: a) } 10 \text { bus stop locations on all bus lines that pass within any } \\
\text { part of a } 402-\mathrm{m}(0.25 \text {-mile) straight-line radius around the study site, } \\
\text { or b) } 5 \text { individual train stop locations on all train lines that pass within } \\
\text { any part of a } 804-\mathrm{m} \text { ( } 0.5 \text {-mile) radius around the study site } \\
\text { - Models are recommended only for sites that meet at least one of the two } \\
\text { following smart-growth pedestrian or bicycle criteria: } \\
\text { o There is at least one designated bicycle facility within two blocks of the } \\
\text { edge of the site } \\
\text { o There is }>50 \% \text { sidewalk coverage on streets within a } 402-\mathrm{m}(0.25 \text {-mile) } \\
\text { straight-line radius of the site }\end{array}$ \\
\hline
\end{tabular}

Notes:

1 ITE Land-Use Codes are from the ITE Trip Generation Manual, ninth edition, 2012.

2 The P.M. model was developed using several retail land uses (with ITE Land-Use Codes 820, 867, and 880), so it could be appropriate for these classifications. It could also be appropriate for other retail uses (e.g., 813, 814, and 815) that are likely to experience vehicle trip reductions similar to the reductions experienced by residential, office, restaurant, and coffee/donut shop uses when they are located in smart-growth areas. However, the P.M. model should be applied with caution to other types of retail land uses (e.g., a retail store that sells heavy goods may generate motor vehicle trip numbers similar to standard ITE predictions even if it is in a smart-growth area). Note that the A.M. model does not apply to retail uses.

3 This criterion is necessary to avoid applying the models in locations that may have abnormally high trip activity.

${ }^{4}$ The minimum values for jobs and residents are based on characteristics of the study sites used for model development. Both inequalities are based on empirical data.

${ }^{5}$ Designated bicycle facilities include multi-use trails, cycle tracks, and bicycle lanes; they do not include shared lane markings or basic bicycle route signs without any other facilities.

collect more data to increase the sample size for analysis, test additional variables (e.g., measures of landuse mix; proximity to important activity centers besides the regional central business district), and create separate adjustment models for each broad land-use category (e.g., a residential model, an office model, 


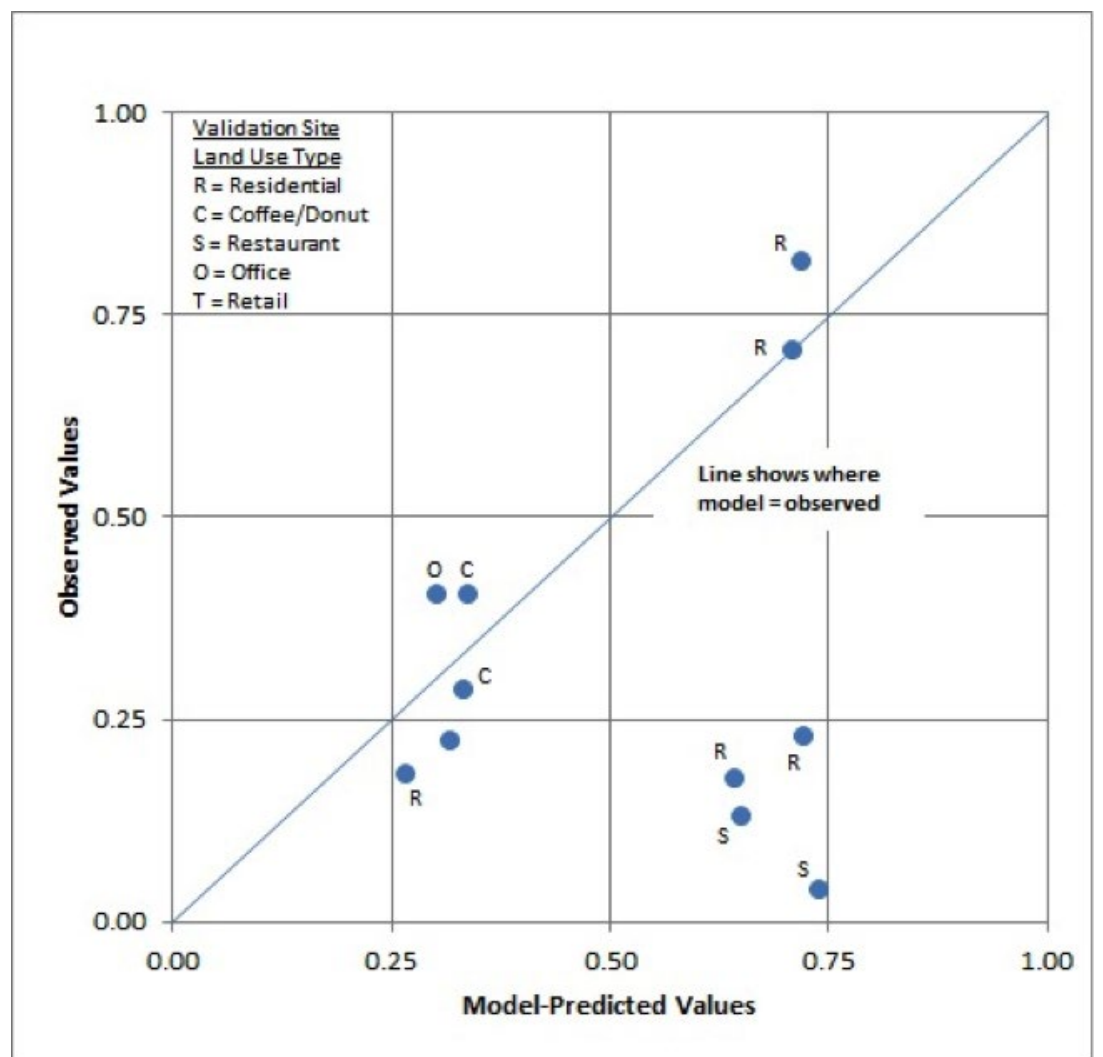

Figure 1: A.M. model validation: Observed vs. model-predicted values.

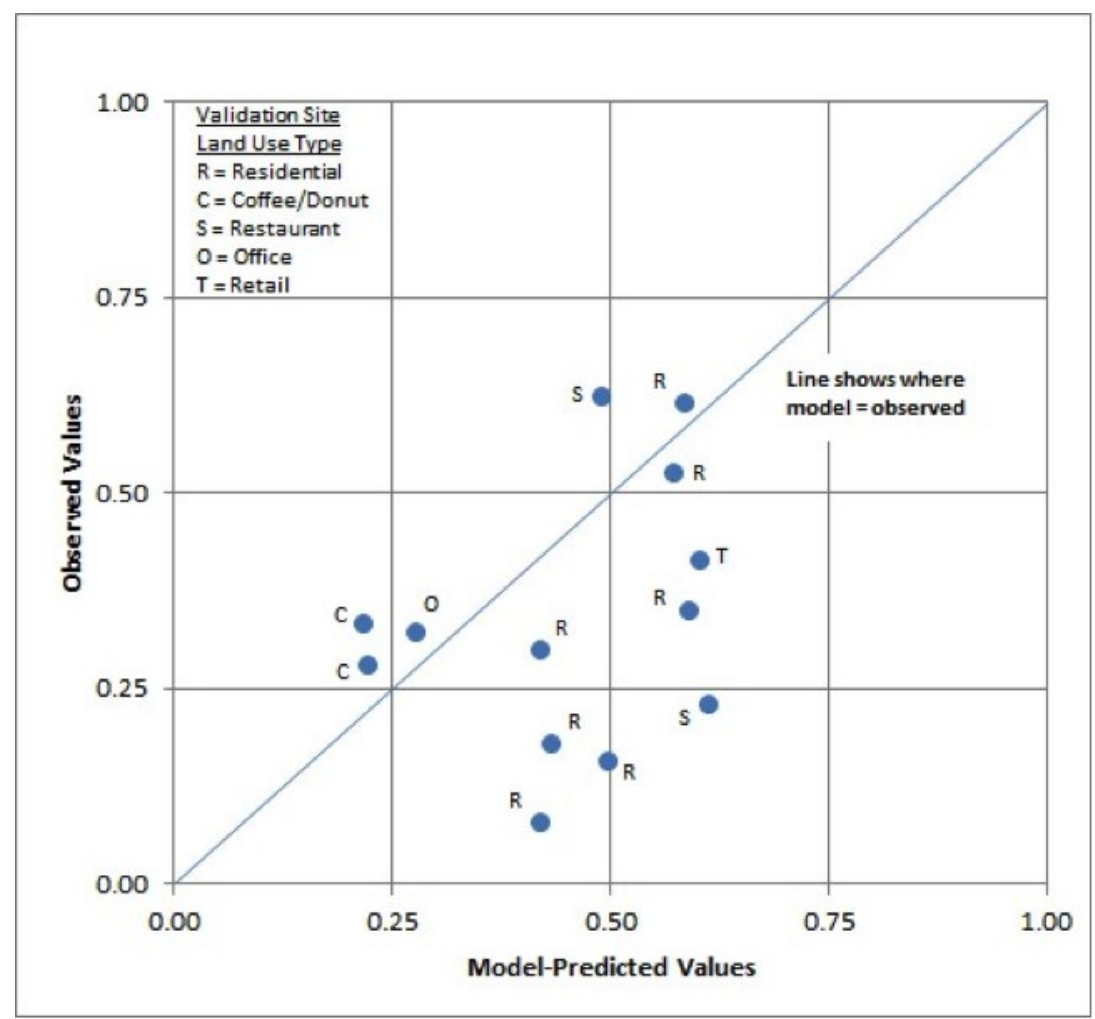

Figure 2: P.M. model validation: Observed vs. model-predicted values. 
a coffee shop model, and a model that could be used for whole multi-use developments). While the models were based on data collected in California, the methodological approach provides a framework for adjusting ITE trip-generation estimates in smart-growth areas outside of California.

The next edition of the ITE Trip Generation Handbook is likely to support a person-trip-based approach for trip-generation analysis. Therefore, the research team also considered developing smartgrowth trip-generation models based on the percentage of trips made by walking, bicycling, and public transit at each site. However, 16 sites in the dataset only had vehicle-trip counts and did not include trips by mode, so they would have been removed from the analysis. This exclusion of sites would have made the dataset too small to develop reliable models. Future data collection efforts should capture person-trip data so that this information can be used to develop multimodal trip-generation models for smart-growth areas.

Future studies could compare the accuracy and applicability of the method described in this paper with other recently developed trip-generation adjustment methods. This would include comparing the trip-generation estimates from each method to ground-truth counts and evaluating ease of use for practitioners, for example, using the method employed by Shafizadeh et al. (2012). These comparisons could eventually suggest refinements to improve each individual method or lead to a combined method with greater predictive power.

\section{Conclusion}

This paper presents models that can be used to adjust ITE motor-vehicle trip-generation estimates at smart-growth sites based on specific contextual characteristics. One model applies to the A.M. peak hour and the other applies to the P.M. peak hour. It is likely that the small-sample models were not able to account for all of the complex variation in sites, including different levels of economic activity at particular locations. For sites where the models did not predict vehicle trip generation well, validation checks showed that the models provided conservative vehicle-trip reductions (i.e., overestimated vehicle trips compared to actual counts at most validation sites). While the models are not without their caveats, they represent a significant step forward in developing methods to adjust ITE vehicle trip-generation estimates in locations with smart-growth characteristics.

\section{Acknowledgments}

This study was funded by the Division of Research and Innovation of the California Department of Transportation under the direction of Project Manager Terry Parker. The authors would like to thank Brian Bochner, with the Texas Transportation Institute, for his assistance throughout the project as well as Ewald and Wasserman Research Consultants, Gene Bregman and Associates, Manpower Inc., and Calvin Thigpen and Mary Madison Campbell, both with the University of California, Davis, for their assistance with aspects of the data collection and analysis process. The contents of this paper reflect the views of the authors, who are responsible for the facts and accuracy of the data presented herein. The contents do not necessarily reflect the official views or policies of the state of California. 


\section{References}

Arrington, G. B., and R. Cervero. 2008. Effects of TOD on Housing, Parking, and Travel. Transit Cooperative Research Program Report 128. URL: http://144.171.11.107/Main/Public/Blurbs/160307 .aspx.

Bochner, B. S., K. Hooper, B. Sperry, and R. Dunphy. 2011. Enhancing Internal Trip Capture Estimation for Mixed-use Developments. National Cooperative Highway Research Program (NCHRP). URL: http://onlinepubs.trb.org/onlinepubs/nchrp/nchrp_rpt_684.pdf.

Cervero, R., and K. Kockelman. 1997. Travel demand and the 3Ds: Density, diversity, and design. Transportation Research Part D: Transport and Environment 2(3): 199-219.

City and County of San Francisco Planning Department. 2002. Transportation impact analysis guidelines for environmental review. URL: http://www.sfplanning.org/Modules/ShowDocument .aspx?documentid=6753.

Clifton, K. J., K. M. Currans, A. C. Cutter, and R. J. Schneider. 2012a. Household travel surveys in context-based approach for adjusting ITE trip generation rates in urban contexts. Transportation Research Record 2307: 108-119.

Clifton, K. J., K. M. Currans, and C. Muhs. 2012b. Contextual influences on trip generation, prepared for Oregon Transportation Research and Education Consortium, Portland, OR.

Costello, A. B. and J. W. Osborne. 2005. Best practices in exploratory factor analysis: Four recommendations for getting the most from your analysis. Practical Assessment, Research and Evaluation 10(7): 1-9. URL: http://pareonline.net/getvn.asp?v $=10 \& n=7$.

Ewing, R., and R. Cervero. 2010. Travel and the built environment: A meta-analysis. Journal of the American Planning Association 76(3): 265-294.

Handy, S. L., X. Cao, and P. L. Mokhtarian. 2008. The causal influence of neighborhood design on physical activity within the neighborhood: Evidence from Northern California. American Journal of Health Promotion 22(5): 350-358.

Institute of Transportation Engineers. 2004. Trip Generation Handbook: An ITE recommended practice. Second edition, Hooper, K. G. (Ed.). Washington, DC: ITE.

Institute of Transportation Engineers. 2012. Trip Generation Manual. Ninth edition. Washington, DC: ITE.

Jones and Stokes Associates. 2007. Software User's Guide: URBEMIS2007 for Windows. URL: http:// urbemis.com/software/URBEMIS9\%20Users\%20Manual\%20Main\%20Body.pdf.

Kimley-Horn and Associates, Inc. in association with Economic and Planning Systems and Gene Bregman and Associates. 2009. Trip-generation rates for urban infill land uses in California, phase 2: Data collection prepared for California Department of Transportation. URL: http://www.dot .ca.gov/research/researchreports/reports/2009/final_summary_report-calif._infill_trip-generation_ rates_study_july_2009.pdf.

Levinson, D. M., and K. J. Krizek. 2008. Planning for place and plexus: Metropolitan land use and transport. New York: Routledge.

Metropolitan Transportation Commission. 2006. Station area residents survey (StaRS). Oakland, CA: MTC.

Muldoon, D., and L. Bloomberg. 2008. Development of best practices for traffic impact studies. Transportation Research Record 2077: 32-38.

New Zealand Trips and Parking Database Bureau. 2013. The New Zealand trips database. URL: http:// www.tdbonline.org. 
Rizavi, A., and A. Yeung. 2010. Urban commuting trends-comparing trip generation practices. Institute of Transportation Engineers. Presented at Institute of Transportation Engineers annual meeting and exhibit, Vancouver, BC. URL: http://www.ite.org/Membersonly/annualmeeting/2010/ AB10H3201.pdf.

Rodríguez, D. A., S. Aytur, A. Forsyth, J. M. Oakes, and K. J. Clifton. 2008. Relation of modifiable neighborhood attributes to walking. Preventative Medicine 47(3): 260-264.

San Diego Association of Governments (SANDAG). 2010. Trip generation for smart growth: Planning tools for the San Diego Region. URL: http://www.sandag.org/uploads/publicationid/publicationid_1500_11604.pdf.

Schneider, R .J., K. Shafizadeh, B. R. Sperry, and S. L. Handy. 2013a. Methodology to gather multimodal trip generation data in smart-growth areas. Transportation Research Record. Forthcoming.

Schneider, R., K. Shafizadeh, B. Sperry, B. Bochner, and S. Handy. 2013b. California smart growth trip generation rates study, Appendix E: Data collection methodology and results. University of California, Davis, for the California Department of Transportation. URL: http://ultrans.its.ucdavis.edu/ projects/smart-growth-trip-generation.

Schneider, R., K. Shafizadeh, and S. Handy. 2013c. California smart growth trip generation rates study, Appendix F: Methodology for adjusting ITE trip generation estimates for smart growth projects. University of California, Davis, for the California Department of Transportation. URL: http://ultrans.its.ucdavis.edu/projects/smart-growth-trip-generation.

Shafizadeh, K., R. Lee, D. Niemeier, T. Parker, and S. Handy. 2012. Evaluation of operation and accuracy of available smart growth trip generation methodologies for use in California. Transportation Research Record 2307: 120-131.

Steiner, R. 1998. Trip generation and parking requirements in traditional shopping districts. Transportation Research Record 1617: 28-37.

Tindale Oliver and Associates, in association with Cumbey and Fair Inc., MTP Group Inc., Resource Systems Group Inc., and Tinter Associates Inc. 1993. FDOT Trip Characteristics Study of Multi-use Developments. Prepared for the Florida Department of Transportation, FDOT District IV. URL: http://www.dot.state.fl.us/planning/systems/sm/siteimp/PDFs/1993intcap.pdf.

Trip rate information computer system, United Kingdom. 2013. URL: http://www.trics.org.

United States Environmental Protection Agency. 2013. Trip generation tool for mixed-use developments. URL: http://www.epa.gov/smartgrowth/mxd_tripgeneration.html. 